\title{
Epidemiological aspects of respiratory symptoms treated in the emergency room of a tertiary care hospital*
}

\author{
Perfil epidemiológico dos atendimentos de emergência \\ por sintomas respiratórios em um hospital terciário
}

\author{
Denise Rossato Silva, Vinícius Pellegrini Viana, Alice Mânica Müller, \\ Ana Cláudia Coelho, Gracieli Nadalon Deponti, Fernando Pohlmann Livi, \\ Paulo de Tarso Roth Dalcin
}

\begin{abstract}
Objective: To evaluate the prevalence of respiratory symptoms as the motive for emergency room visits by adult and pediatric patients, describing the major clinical syndromes diagnosed and the outcomes of the patients. Methods: A cross-sectional study conducted in the emergency room of a tertiary care university hospital. Between November of 2008 and November of 2009, we reviewed the total number of emergency room visits per day. Children and adults who presented with at least one respiratory symptom were included in the study. The electronic medical records were reviewed, and the major characteristics of the patients were recorded. Results: During the study period, there were 37,059 emergency room visits, of which 11,953 (32.3\%) were motivated by respiratory symptoms. The prevalence of emergency room visits due to respiratory symptoms was $28.7 \%$ and $38.9 \%$ among adults and children, respectively. In adults, the rates of hospitalization and mortality were $21.2 \%$ and $2.7 \%$, respectively, compared with $11.9 \%$ and $0.3 \%$, respectively, in children. Among the adults, the time from symptom onset to emergency room visit correlated positively with the need for hospitalization $(p<0.0001)$, the length of the hospital stay $(p<0.0001)$, and the mortality rate $(p=0.028)$. Conclusions: We found a high prevalence of respiratory symptoms as the motive for emergency room visits by adult and pediatric patients. Our results could inform decisions regarding the planning of prevention measures. Further epidemiological studies are needed in order to clarify the risk factors for severe respiratory symptoms.
\end{abstract}

Keywords: Emergency service, hospital; Respiratory tract diseases; Respiratory tract infections; Signs and symptoms, respiratory.

\section{Resumo}

Objetivo: Avaliar a prevalência de sintomas respiratórios como motivo para procura de atendimento de emergência por pacientes adultos e pediátricos, descrevendo as principais síndromes clínicas diagnosticadas e o desfecho dos pacientes. Métodos: Estudo transversal, realizado na emergência de um hospital universitário terciário. Entre novembro de 2008 e novembro de 2009, o número total de atendimentos foi revisado diariamente. Foram incluídos no estudo crianças e adultos com pelo menos um sintoma respiratório. Os prontuários eletrônicos foram revisados e foram registradas as principais características dos pacientes. Resultados: Durante o período do estudo, houve 37.059 admissões na emergência, das quais 11.953 (32,3\%) foram motivadas por sintomas respiratórios. A prevalência de atendimentos por sintomas respiratórios foi $28,7 \%$ e 38,9\% nos adultos e crianças, respectivamente. As taxas de internação hospitalar e de mortalidade nos adultos foram $21,2 \%$ e $2,7 \%$, respectivamente, comparadas com 11,9\% e 0,3\%, respectivamente, nas crianças. Nos adultos, quanto maior o tempo entre o início dos sintomas e a visita à emergência, maiores foram a necessidade de hospitalização ( $p<0,0001)$, o tempo de hospitalização $(p<0,0001)$ e a mortalidade $(p=0,028)$. Conclusões: Encontramos uma prevalência elevada de atendimentos por sintomas respiratórios entre os pacientes adultos e pediátricos. Nossos resultados podem contribuir para o planejamento de medidas de prevenção. Futuros estudos epidemiológicos poderão colaborar para a melhor elucidação dos fatores de risco para a presença de sintomas respiratórios nesses pacientes.

Descritores: Serviço hospitalar de emergência; Doenças respiratórias; Infecções respiratórias; Sinais e sintomas respiratórios.

\footnotetext{
* Study carried out at the Hospital de Clínicas de Porto Alegre, Porto Alegre, Brazil.

Correspondence to: Denise Rossato Silva. Rua Ramiro Barcelos, 2350, Santa Cecília, CEP 90035-903, Porto Alegre, RS, Brasil. Tel. 5551 3359-8241. E-mail: denise.rossato@terra.com.br

Financial support: This study received financial support from the Fundo de Incentivo à Pesquisa da Sociedade Brasileira de Pneumologia e Tisiologia (FIPE-SBPT, Research Incentive Fund of the Brazilian Thoracic Association), the Fundo de Incentivo à Pesquisa do Hospital de Clínicas de Porto Alegre (FIPE-HPCA, Research Incentive Fund of the Hospital de Clínicas de Porto Alegre), and the Fundação de Amparo à Pesquisa do Rio Grande do Sul (FAPERGS, Foundation for the Support of Research in the State of Rio Grande do Sul).
}

Submitted: 2 October 2012. Accepted, after review: 16 November 2012. 


\section{Introduction}

The prevalence of respiratory symptoms in a given population is an indirect indicator of acute and chronic respiratory diseases, an indicator that is quite reliable from an epidemiological standpoint. ${ }^{(1,2)}$ Respiratory diseases are a leading cause of death among adults and children, accounting for $12 \%$ of all deaths worldwide. ln low- and middle-income countries, upper respiratory tract infections (URTls) account for $11.3 \%$ and $5.4 \%$ of all deaths, respectively. ${ }^{(3)}$

In addition to exerting enormous pressure on health services, respiratory diseases are common causes of school and work absenteeism. In Brazil, chronic and acute respiratory diseases collectively rank second among the leading causes of hospitalization within the Brazilian Unified Health Care System, accounting for approximately $14 \%$ of all hospitalizations within the system. In southern Brazil, respiratory diseases are the leading cause of hospitalization (accounting for $17 \%$ of all hospital admissions).(4)

Respiratory complaints are the motive for a large proportion of outpatient visits, emergency room visits, and hospitalizations. ${ }^{(5)}$ A study conducted in a developing country ${ }^{(6)}$ showed that $10 \%$ of all emergency room visits were due to respiratory diseases. In a two-year study conducted in the city of Gama, Brazil, ${ }^{(7)} 641,905$ emergency room visits were evaluated, 37,642 (5.8\%) of which were found to be due to respiratory complaints. Studies on the pattern of emergency room visits by individuals with respiratory symptoms are important, because they could inform decisions regarding the organization and planning of health services in order to meet this demand. ${ }^{(6,7)}$ The objective of the present study was to evaluate the prevalence of respiratory symptoms as the motive for emergency room visits by adult and pediatric patients at a tertiary care hospital, describing the major clinical syndromes diagnosed and the patient outcomes.

\section{Methods}

This was a cross-sectional study conducted in the emergency room of the Hospital de Clínicas de Porto Alegre (HCPA), located in the city of Porto Alegre, southern Brazil. The HCPA is a general tertiary care university hospital with 750 beds and approximately 30,000 admissions per year. The city of Porto Alegre has 1,409,939 inhabitants, and the surrounding metropolitan area includes 31 cities, the total population of the greater metropolitan area being 3,979,561. The Research Ethics Committee of the HCPA granted the researchers access to patient medical records. A waiver of consent was approved, and the researchers signed a confidentiality agreement.

Children and adults who presented to the emergency room with at least one respiratory symptom were included in the study. During the study period (between November of 2008 and November of 2009), we reviewed the total number of visits per day to the pediatric and adult sections of the emergency room of the HCPA. The electronic medical records were reviewed, and the characteristics of the patients treated for respiratory symptoms that were recorded included gender, age, race, smoking history, comorbidities, respiratory symptoms, and familial history of flu symptoms. The respiratory symptoms considered were rhinorrhea, nasal congestion, odynophagia, dysphonia, cough, breathlessness, wheezing, chest pain, and fever. The patients who presented with fever alone were not included in the study. Clinical findings on admission (axillary temperature, HR, RR, pulmonary auscultation findings, and $\mathrm{SpO}_{2}-$ measured by digital pulse oximetry) were also recorded, as were the major clinical syndromes diagnosed and the patient outcomes (ICU admission, ward admission, discharge from the emergency room, and death).

Data were entered into a Microsoft Excel 2007 database, after which they were processed and analyzed with the Statistical Package for the Social Sciences, version 18.0 (SPSS Inc., Chicago, IL, USA). We performed a descriptive analysis of the overall prevalence of visits by patients with respiratory symptoms to the pediatric and adult sectors of the emergency room (for patients $<14$ and $\geq 14$ years of age, respectively). We stratified the time from symptom onset to emergency room visit (as $<7$ days, 7-21 days, and $>21$ days), as well as evaluating the major respiratory symptoms, the major clinical diagnoses, the length of the emergency room visit, the rate of admission to the hospital, the rate of $1 \mathrm{CU}$ admission, the rate of discharge from the emergency room, and the mortality rate. 


\section{Results}

During the 12-month study period, there were 37,059 emergency room visits $(24,189$ by adults and 12,870 by children), of which $11,953(32.3 \%)$ were motivated by respiratory symptoms. The monthly variation in the number of emergency room visits due to respiratory symptoms is shown in Figures 1 and 2. There was an increase in the number of such visits in April, May, and June. The prevalence of visits due to respiratory symptoms was $28.7 \%$ $(6,942 / 24,189)$ among adult patients and 38.9\% $(5,011 / 12,870)$ among pediatric patients. The

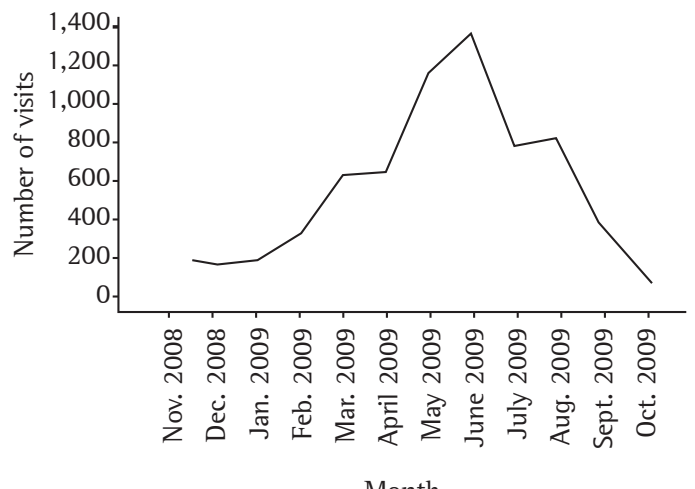

Figure 1 - Monthly variation in the number of visits to the adult sector of the Hospital de Clínicas de Porto Alegre emergency room (for patients $\geq 14$ years of age) motivated by respiratory symptoms, between November of 2008 and November of 2009.

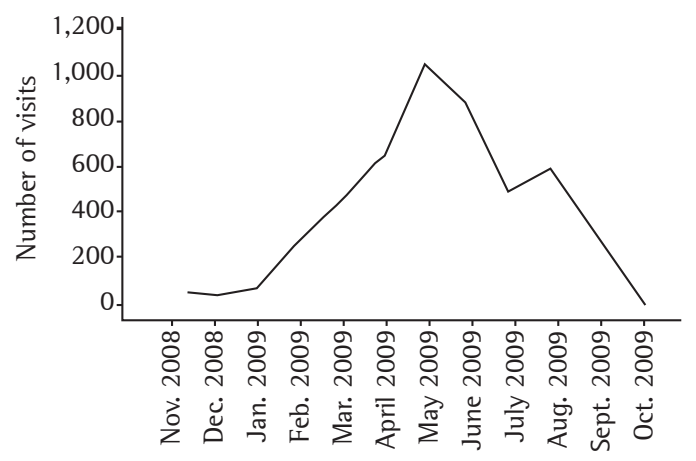

Month

Figure 2 - Monthly variation in the number of visits to the pediatric sector of the Hospital de Clínicas de Porto Alegre emergency room (for patients $<14$ years of age) motivated by respiratory symptoms, between November of 2008 and November of 2009. most common symptoms were cough (in 73.4\%), fever (in 56.1\%), breathlessness (in 40.9\%), chest pain (in 24.5\%), and rhinorrhea (20.9\%). The median duration of symptoms prior to admission was 3 days (interquartile range: 1-6 days). A total of 2,205 patients (18.5\%) admitted to the emergency room required hospitalization. of those, $242(2.0 \%)$ required ICU admission. The overall mortality rate among all study participants was $2.3 \%(280 / 11,953)$. The demographic and clinical characteristics of the study population (adults and children) are shown in Table 1.

Table 2 shows the characteristics of the adult patients and the analysis of these characteristics on the basis of the time from symptom onset to emergency room visit. Because data on the time from symptom onset to emergency room visit were not available for all patients, the analysis included only 4,434 patients. Of those 4,434 patients, $939(21.2 \%)$ were admitted to the hospital and 120 (2.7\%) died. The median (interquartile range) length of emergency room visit and the median (interquartile range) total length of hospital stay were 0.5 day (0.5-1.0 day) and 0.5 day (0.5-3.0 days), respectively. The patients who had a 6-day or shorter history of respiratory symptoms ( $<7$ group) were younger than those who had a 7- to 21-day history (7-21 group) and those who had a 21-day or longer history ( $>21$ group; $44.9 \pm 20.4$ years vs. $49.4 \pm 19.7$ years and $49.9 \pm 17.6$ years; $\mathrm{p}<0.0001)$. A longer time from symptom onset to emergency room visit correlated with a lower level of education of the patients $(p<0.0001)$. When the proportion of patients who were residents of the city of Porto Alegre was higher, the time from symptom onset to emergency room visit was shorter $(p=0.012)$. Rhinorrhea, odynophagia, and fever were most common in the patients in the $<7$ group, whereas cough and breathlessness were most common in those in the 7-21 group. The number of patients with asthma was highest in the $<7$ group $(p=0.002)$, and the number of patients with HIV infection was highest in the $>21$ group ( $p<0.0001)$. Among the patients who underwent chest X-ray, normal results were more common in those in the $<7$ group ( $p<0.0001)$, and a consolidation pattern was more common in those in the 7-21 group ( $p=0.002)$. Pleural effusion and diffuse infiltrates were most common in the $>21$ group ( $p=0.008$ and $p=0.003$, respectively). The 
Table 1 - Principal characteristics of the patients. ${ }^{a}$

\begin{tabular}{|c|c|c|}
\hline \multirow[t]{2}{*}{ Characteristic } & Adults & Children \\
\hline & $(\mathrm{n}=6,942)$ & $(\mathrm{n}=5,011)$ \\
\hline Age, years ${ }^{b}$ & $50.0(30.0-55.0)$ & $2.0(0.8-5.0)$ \\
\hline Male gender & $3,125(45.0)$ & $2,795(55.8)$ \\
\hline White & $5,941(85.6)$ & $4,007(80.0)$ \\
\hline$>8$ years of schooling & $3,129(51.2)$ & - \\
\hline \multicolumn{3}{|l|}{ Place of residence } \\
\hline Porto Alegre & $4,815(69.4)$ & $3,635(72.5)$ \\
\hline Greater metropolitan area of Porto Alegre & $1,851(26.7)$ & $1,247(24.9)$ \\
\hline Interior of the state of Rio Grande do Sul & $276(3.9)$ & $129(2.6)$ \\
\hline \multicolumn{3}{|l|}{ Symptom upon arrival at the emergency room } \\
\hline Cough & $4,553(65.6)$ & 4,214 (84.1) \\
\hline Breathlessness & $3,521(50.7)$ & $1,363(27.2)$ \\
\hline Chest pain & $2,697(38.9)$ & $229(4.6)$ \\
\hline Rhinorrhea & $676(9.7)$ & $1.821(36.3)$ \\
\hline Nasal congestion & $263(3.8)$ & $673(13.4)$ \\
\hline Odynophagia & 897 (12.9) & $472(9.4)$ \\
\hline Dysphonia & $102(1.5)$ & $60(1.2)$ \\
\hline Wheezing & $264(3.8)$ & $760(15.2)$ \\
\hline Fever & $2,986(43.0)$ & $3,718(74.2)$ \\
\hline Hemoptysis & $186(2.7)$ & $4(0.1)$ \\
\hline Duration of symptoms prior to arrival at the emergency room, days & $3.0(1.0-7.0)^{\mathrm{c}}$ & $2.0(1.0-4.0)^{\mathrm{c}}$ \\
\hline \multicolumn{3}{|l|}{ Comorbidity } \\
\hline Systemic arterial hypertension & $1,730(24.9)$ & 0 \\
\hline Asthma & $603(8.7)$ & $777(15.5)$ \\
\hline COPD & $730(10.5)$ & 0 \\
\hline Ischemic heart disease & $567(8.2)$ & 0 \\
\hline Heart failure & $554(8.0)$ & 0 \\
\hline Diabetes mellitus & $900(13.0)$ & $6(0.1)$ \\
\hline HIV infection & $400(5.8)$ & $32(0.6)$ \\
\hline Cancer & $632(9.1)$ & $48(1.0)$ \\
\hline Chronic renal failure & $231(3.3)$ & 0 \\
\hline \multicolumn{3}{|l|}{ Smoking status } \\
\hline Nonsmoker & $143(2.1)$ & 0 \\
\hline Former smoker & $712(10.3)$ & 0 \\
\hline Current smoker & $611(8.8)$ & 0 \\
\hline
\end{tabular}

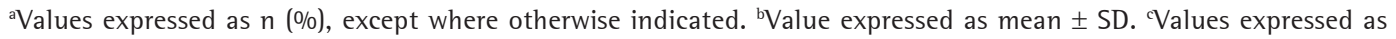
median (interquartile range).

most common diagnoses in the $<7$ group were influenza (in 18.2\%), pneumonia (in 12.6\%), and URTI (in 12.2\%). In the 7-21 group, the most common diagnoses were pneumonia (in 17.8\%), URT1 (in 10.7\%), and COPD exacerbation (in 9.6\%); whereas the most common diagnoses in the $>21$ group were pneumonia (in 9.1\%), COPD exacerbation (in 5.2\%), and sinusitis (in 4.3\%). The length of emergency room visit was shortest among the patients in the $<7$ group ( $p$ $<0.0001)$. A longer time from symptom onset to emergency room visit correlated with a greater need for hospitalization ( $p<0.0001)$, longer hospital stays ( $<<0.0001)$, and higher mortality $(p=0.028)$.

Table 3 shows the characteristics of the pediatric patients and the analysis of those characteristics on the basis of the time from symptom onset to emergency room visit. Because, as was true for adults, data on the time from symptom onset to emergency room visit were not available for the entire group of pediatric patients, 
Table 2 - Characteristics of the adult patients and analysis based on the time from onset of respiratory symptoms to emergency room visit. $^{\text {a }}$

\begin{tabular}{|c|c|c|c|c|c|}
\hline \multirow{3}{*}{ Characteristic } & \multirow[t]{2}{*}{ Total } & \multicolumn{3}{|c|}{$\begin{array}{c}\text { Time from symptom onset to } \\
\text { emergency room visit }\end{array}$} & \multirow[t]{3}{*}{$\mathrm{p}$} \\
\hline & & $<7$ days & 7-21 days & $>21$ days & \\
\hline & $(n=4,434)$ & $(n=3,024)$ & $(n=1,179)$ & $(n=230)$ & \\
\hline Age, years ${ }^{b}$ & $46.4 \pm 20.2$ & $44.9 \pm 20.4^{*, * * *}$ & $49.4 \pm 19.7^{*}$ & $49.9 \pm 17.6^{* * *}$ & $<0.0001$ \\
\hline Male gender & $1,961(44.2)$ & $1,355(44.8)$ & $500(42.4)$ & $106(46.1)$ & 0.317 \\
\hline White & $3,791(85.5)$ & $2,600(86.0)$ & $598(84.6)$ & $193(83.9)$ & 0.438 \\
\hline$>8$ years of schooling & $2,103(53.5)$ & $1,506(55.8)^{*, * *}$ & $498(48.4)^{* * * * * *}$ & $99(48.1)^{* * * * * * *}$ & $<0.0001$ \\
\hline \multicolumn{6}{|l|}{ Place of residence } \\
\hline Porto Alegre & $3,110(70.1)$ & $2,162(71.5)^{* * * *}$ & $799(67.8)^{*, * * *}$ & $149(64.8)^{* *, * * * *}$ & 0.012 \\
\hline $\begin{array}{l}\text { Greater metropolitan area of } \\
\text { Porto Alegre }\end{array}$ & $1,174(26.5)$ & 777 (25.7) & $329(27.9)$ & 68 (29.6) & 0.189 \\
\hline $\begin{array}{l}\text { Interior of the state of Rio } \\
\text { Grande do Sul }\end{array}$ & $150(3.4)$ & $86(2.8)^{*, * *}$ & $51(4.3)^{* * * *}$ & $13(5.7)^{* * * * * * *}$ & 0.009 \\
\hline \multicolumn{6}{|l|}{$\begin{array}{l}\text { Symptom upon arrival at the } \\
\text { emergency room }\end{array}$} \\
\hline Cough & $3,132(70.6)$ & $2,069(68.4)^{*, * * *}$ & $906(76.8)^{*, * * * *}$ & $157(68.3)^{* * * * * * *}$ & $<0.0001$ \\
\hline Expectoration & $1,946(28.0)$ & $795(26.3)^{*}$ & $445(37.7)^{*, * * * *}$ & $60(26.1)^{* * *}$ & $<0.0001$ \\
\hline Breathlessness & $2,071(46.7)$ & $1,335(44,1)^{*, * * *}$ & $621(52.7)^{*, * * * *}$ & $115(50.0)^{* *, * * * *}$ & $<0 . .001$ \\
\hline Chest pain & $1,841(41.5)$ & $1,249(41.3)$ & $495(42.0)$ & $97(42.2)$ & 0.900 \\
\hline Rhinorrhea & $538(12.1)$ & $422(14.0)^{*, * * *}$ & $102(8.7)^{*, * * * *}$ & $14(6.1)^{* * * * * * *}$ & $<0.0001$ \\
\hline Nasal congestion & $203(4.6)$ & $148(4.9)$ & $49(4.2)$ & $6(2.6)$ & 0.201 \\
\hline Odynophagia & $683(15.4)$ & $547(18.1)^{*, * * *}$ & $124(10.5)^{*, * * * *}$ & $12(5.2)^{* * * * * * *}$ & $<0.0001$ \\
\hline Dysphonia & $75(1.7)$ & $49(1.6)$ & $25(2.1)$ & $1(0.4)$ & 0.167 \\
\hline Wheezing & $166(3.7)$ & $113(3.7)$ & $47(4.0)$ & $6(2.6)$ & 0.602 \\
\hline Fever & $2,240(50.5)$ & $1,645(54.4)^{*, * * *}$ & $518(43.9)^{*, * * * *}$ & $77(33.5)^{* * * * * * *}$ & $<0.0001$ \\
\hline Hemoptysis & $118(2.7)$ & $75(2.5)$ & $35(3.0)$ & $8(3.5)$ & 0.494 \\
\hline \multicolumn{6}{|l|}{ Comorbidity } \\
\hline Systemic arterial hypertension & $1,071(24.2)$ & $698(23.1)^{*, * *}$ & $316(26.8)^{*, * * * *}$ & $57(24.8)^{* * * * * * *}$ & 0.039 \\
\hline Asthma & $389(8.8)$ & $291(9.6)^{*, * * *}$ & $90(7.6)^{* * * * *}$ & $8(3.5)^{* * * * * * *}$ & 0.002 \\
\hline COPD & $381(8.6)$ & $249(8.2)^{*, * * *}$ & $122(10.3)^{*, * * * *}$ & $10(4.3)^{* * * * * *}$ & 0.006 \\
\hline lschemic heart disease & $357(8.1)$ & $261(8.6)$ & $83(7.0)$ & $13(5.7)$ & 0.092 \\
\hline Heart failure & $310(7.0)$ & $212(7.0)$ & $90(7.6)$ & $8(3.5)$ & 0.078 \\
\hline Diabetes mellitus & $542(12.2)$ & $376(12.4)$ & $136(11.5)$ & $30(13.0)$ & 0.675 \\
\hline HIV infection & $278(6.3)$ & $150(5.0)^{*, * * *}$ & $95(8.1)^{*, * * * *}$ & $33(14.3)^{* * * * * * *}$ & $<0.0001$ \\
\hline Cancer & $302(6.8)$ & $202(6.7)$ & $88(7.5)$ & $12(5.2)$ & 0.407 \\
\hline Chronic renal failure & $133(3.0)$ & $95(3.1)$ & $32(2.7)$ & $6(2.6)$ & 0.720 \\
\hline \multicolumn{6}{|l|}{ Smoking status } \\
\hline Nonsmoker & $107(45.0)$ & $64(43.5)$ & $32(49.2)$ & $11(42.3)$ & 0.714 \\
\hline Former smoker & $452(81.7)$ & $299(88.5)$ & $124(87.9)$ & $29(76.3)$ & 0.112 \\
\hline Current smoker & $405(87.4)$ & $248(81.0)$ & $128(85.3)$ & $29(72.5)$ & 0.160 \\
\hline \multicolumn{6}{|l|}{ Radiological pattern } \\
\hline Normal & $881(38.7)$ & $593(41.8)^{*, * *}$ & $241(34.2)^{*, * * * *}$ & $47(30.9)^{* * * * * * *}$ & $<0.0001$ \\
\hline Consolidation & $498(21.9)$ & $298(21.0)^{*, * *}$ & $180(25.5)^{*, * * * *}$ & $20(13.2)^{* * * * * * * *}$ & 0.002 \\
\hline Diffuse infiltrate & $114(5.0)$ & $57(4.0)^{*, * * *}$ & $42(6.0)^{*, * * *}$ & $15(9.9)^{* *, * * * *}$ & 0.003 \\
\hline Pleural effusion & $176(7.7)$ & $91(6.4)^{*, * *}$ & $68(9.7)^{*, * * * *}$ & $17(11.2)^{* * * * * * *}$ & 0.008 \\
\hline \multicolumn{6}{|l|}{ Primary diagnosis } \\
\hline URTI & $503(11.3)$ & $368(12.2)^{*, * *}$ & $126(10.7)^{*, * * * *}$ & $9(3.9)^{* *, * * * *}$ & 0.001 \\
\hline Pneumonia & $612(13.8)$ & $381(12.6)^{*, * * *}$ & $210(17.8)^{*, * * * *}$ & $21(9.1)^{* *, * * * *}$ & $<0.0001$ \\
\hline Influenza & $614(13.8)$ & $550(18.2)^{*, * *}$ & $64(5.4)^{*, * * * *}$ & $0(0)^{* *, * * *}$ & $<0.0001$ \\
\hline Asthma & $204(4.6)$ & $156(5.2)^{*, * * *}$ & $43(3.6)^{*}$ & $5(2.2)^{* *}$ & 0.022 \\
\hline COPD & $331(7.5)$ & $206(6.8)^{*, * *}$ & $113(9.6)^{*, * * *}$ & $12(5.2)^{* *, * * * *}$ & 0.004 \\
\hline Sinusitis & $227(5.1)$ & $134(4.4)^{*, * *}$ & $83(7.0)^{*, * * *}$ & $10(4.3)^{* *, * * * *}$ & 0.002 \\
\hline Pulmonary tuberculosis & $42(0.9)$ & $13(0.4)^{*, * * *}$ & $13(1.1)^{*}$ & $16(7.0)^{* * *}$ & $<0.0001$ \\
\hline $\begin{array}{l}\text { Length of emergency room visit, } \\
\text { days }^{c}\end{array}$ & $0.5(0.5-1)$ & $0.5(0.5-1)^{*, * *}$ & $0.5(0.5-2)^{*}$ & $0.5(0.5-2)^{* *}$ & $<0.0001$ \\
\hline Need for hospitalization & $939(21.2)$ & $560(18.5)^{*, * *}$ & $303(25.7)^{*, * * * *}$ & $76(33.0)^{* * * * * * *}$ & $<0.0001$ \\
\hline Need for ICU admission & $119(2.7)$ & $70(2.3)$ & $39(3.3)$ & $10(4.3)$ & 0.056 \\
\hline Length of hospital stay, days ${ }^{c}$ & $0.5(0.5-3.0)$ & $7(3-14)^{* * * *+}$ & $10(6-19)^{*, * * *}$ & $14(6-24)^{* *, * * * *}$ & $<0.0001$ \\
\hline Death & $120(2.7)$ & $70(2.3)^{*, * * *}$ & $39(3.3)^{* ; * * * *}$ & $11(4.8)^{* * * * * * *}$ & 0.028 \\
\hline
\end{tabular}


Table 3 - Characteristics of the pediatric patients and analysis based on the time from onset of respiratory symptoms to emergency room visit.

\begin{tabular}{|c|c|c|c|c|c|}
\hline \multirow{3}{*}{ Characteristic } & \multirow[t]{2}{*}{ Total } & \multicolumn{3}{|c|}{$\begin{array}{c}\text { Time from symptom onset to } \\
\text { emergency room visit }\end{array}$} & \multirow{3}{*}{$\mathrm{p}$} \\
\hline & & $<7$ days & 7-21 days & $>21$ days & \\
\hline & $(\mathrm{n}=3,860)$ & $(n=3,242)$ & $(n=574)$ & $(n=44)$ & \\
\hline Age, years ${ }^{b}$ & $2.0(0.8-5.0)$ & $2.0(0.8-5.0)^{* * *}$ & $1.0(0.7-5.0)^{* * * *}$ & $0.9(0.5-3.0)^{* * * * * * * *}$ & 0.023 \\
\hline Male gender & $2,116(54.8)$ & $1,771(54.6)$ & $322(56.1)$ & $23(52.3)$ & 0.762 \\
\hline White & 3,085 (79.9) & 2,602 (80.3) & 447 (77.9) & $36(81.8)$ & 0.401 \\
\hline \multicolumn{6}{|l|}{ Place of residence } \\
\hline Porto Alegre & $2,806(72.7)$ & $2,352(72.5)$ & $420(73.2)$ & $34(77.3)$ & 0.754 \\
\hline $\begin{array}{l}\text { Greater metropolitan area of } \\
\text { Porto Alegre }\end{array}$ & $963(24.9)$ & $815(25.1)$ & $138(24.0)$ & $10(22.7)$ & 0.806 \\
\hline $\begin{array}{l}\text { Interior of the state of Rio } \\
\text { Grande do Sul }\end{array}$ & $91(2.4)$ & $75(2.3)$ & $16(2.8)$ & $0(0)$ & 0.461 \\
\hline \multicolumn{6}{|l|}{$\begin{array}{l}\text { Symptom upon arrival at the } \\
\text { emergency room }\end{array}$} \\
\hline Cough & 3,311 (85.8) & 2,765 (85.3) & $507(88.3)$ & 39 (88.6) & 0.136 \\
\hline Breathlessness & $988(25.6)$ & $837(25.8)$ & $140(24.4)$ & $11(25.0)$ & 0.767 \\
\hline Chest pain & $181(4.7)$ & $151(4.7)$ & $30(5.2)$ & $0(0)$ & 0.280 \\
\hline Rhinorrhea & $1,459(37.8)$ & $1,213(37.4)$ & $233(40.6)$ & $13(29.5)$ & 0.184 \\
\hline Nasal congestion & $544(14.1)$ & $442(13.6)$ & 95 (16.6) & $7(15.9)$ & 0.170 \\
\hline Odynophagia & $374(9.7)$ & $334(10.3)^{*, * * *}$ & $39(6.8)^{*, * * * *}$ & $1(2.3)^{* * * * * * *}$ & 0.008 \\
\hline Dysphonia & $47(1.2)$ & $37(1.1)$ & $9(1.6)$ & $1(2.3)$ & 0.563 \\
\hline Wheezing & $575(14.9)$ & $488(15.1)$ & 77 (13.4) & $10(22.7)$ & 0.203 \\
\hline Fever & $2,985(77,3)$ & $2,554(78.8)^{* * * * *}$ & $406(70.7)^{*, * * *}$ & $25(56.8)^{* * * * * * *}$ & $<0.0001$ \\
\hline \multicolumn{6}{|l|}{ Comorbidity } \\
\hline Asthma & 587 (15.2) & $506(15.6)$ & 74 (12.9) & $7(15.9)$ & 0.246 \\
\hline HIV infection & $25(0.6)$ & $21(0.6)$ & $4(0.7)$ & $0(0)$ & 0.857 \\
\hline Cancer & $35(0.9)$ & $30(0.9)$ & $5(0.9)$ & $0(0)$ & 0.809 \\
\hline History of bronchiolitis & $117(3.0)$ & $98(3.0)$ & $18(3.1)$ & $1(2.3)$ & 0.947 \\
\hline \multicolumn{6}{|l|}{ Radiological pattern } \\
\hline Normal & $651(47.7)$ & $539(48.8)$ & $98(43.8)$ & $14(60.9)$ & 0.210 \\
\hline Consolidation & $300(22.0)$ & $232(20.8)^{* * * * *}$ & $64(28.4)^{*, * * * *}$ & $4(17.4)^{* * * * * * *}$ & 0.035 \\
\hline Diffuse infiltrate & 137 (10.0) & $115(10.3)$ & $19(8.4)$ & $3(13.0)$ & 0.623 \\
\hline \multicolumn{6}{|l|}{ Primary diagnosis } \\
\hline URTI & $980(25.4)$ & $816(25.2)$ & $155(27.0)$ & $9(20.5)$ & 0.487 \\
\hline Pneumonia & $381(9.9)$ & $301(9.3)^{*, * * *}$ & $76(13.2)^{*, * * * *}$ & $4(9.1)^{* * * * * * *}$ & 0.014 \\
\hline Influenza & $356(9.2)$ & $326(10.1)^{* * * *}$ & $28(4.9)^{*, * * * *}$ & $2(4.5)^{* * * * * * *}$ & $<0.0001$ \\
\hline Asthma & $486(12.6)$ & $426(13.1)$ & $56(9.8)$ & $4(9.1)$ & 0.062 \\
\hline Bronchiolitis & $366(9.5)$ & $303(9.3)$ & $57(9.9)$ & $6(13.6)$ & 0.580 \\
\hline Sinusitis & $63(1.6)$ & $43(1.3)^{*, * * *}$ & $18(3.1)^{*, * * * *}$ & $2(4.5)^{* * * * * * *}$ & 0.002 \\
\hline $\begin{array}{l}\text { Length of emergency room visit, } \\
\text { days }^{c}\end{array}$ & $0.5(0.5-0.5)$ & $0.5(0.5-0.5)$ & $0.5(0.5-0.5)$ & $0.5(0.5-0.5)$ & 0.182 \\
\hline Need for hospitalization & $458(11.9)$ & $376(11.6)$ & $73(12.1)$ & $9(20.5)$ & 0.156 \\
\hline Need for ICU admission & $27(0.7)$ & $22(0.7)$ & $5(0.9)$ & $0(0)$ & 0.751 \\
\hline Length of hospital stay, days ${ }^{c}$ & $0.5(0.5-0.5)$ & $6(3-11)$ & $5(3-10)$ & $11(4.5-20.5)$ & 0.179 \\
\hline Mortality rate & $12(0.3)$ & $9(0.3)$ & $3(0.5)$ & $0(0)$ & 0.582 \\
\hline
\end{tabular}

URTI: upper respiratory tract infection. ${ }^{2}$ Values expressed as $n(\%)$, except where otherwise indicated. ${ }^{b}$ Value expressed as mean \pm SD. 'Values expressed as median (interquartile range). *Comparison between the $<7$ days and 7-21 days. ${ }^{* *}$ Comparison between the $<7$ days and $>21$ days. ${ }^{* * *}$ Comparison between the 7-21 days and $>21$ days. 
the analysis included only 3,860 patients. Of those 3,860 patients, $458(11.9 \%)$ were admitted to the hospital and $12(0.3 \%)$ died. The median length of the emergency room visit and median length of hospital stay were equal: 0.5 days (range, 0.5-0.5 days). The pediatric patients in the $>21$ group were younger than were those in the $<7$ and $7-21$ groups $(p=0.023)$. Fever and odynophagia were most common in the patients in the $<7$ group $(p<0.0001$ and $p=$ 0.008 , respectively). In all three of those groups, the most common diagnoses were influenza ( $p$ $<0.0001)$, pneumonia $(p=0.014)$, and sinusitis $(p=0.002)$. Among the pediatric patients, the type of symptom(s) presented did not correlate significantly with the length of emergency room visit, length of hospital stay, or mortality.

\section{Discussion}

In this cross-sectional study, we have described the characteristics of adult and pediatric patients presenting to the emergency room of a tertiary care hospital with respiratory symptoms. In one year, the prevalence of emergency room visits due to respiratory symptoms was $28.7 \%$ and $38.9 \%$ among adult and pediatric patients, respectively. In adults, the rates of hospitalization and mortality were $21.2 \%$ and $2.7 \%$, respectively, compared with $11.9 \%$ and $0.3 \%$, respectively, in children.

In a study conducted at various emergency rooms in a city in ltaly, ${ }^{(8)}$ only $5 \%$ of all visits by adults were motivated by respiratory symptoms. The same percentage was found by another group of authors, ${ }^{(9)}$ who also reported that $47 \%$ of patients presenting to primary care did so because of respiratory symptoms. At 77 basic health care facilities in Algeria, the presence of respiratory symptoms was the motive for seeking medical attention in up to $31.6 \%$ of the cases. ${ }^{(10)}$

In our sample, the number of patients who sought treatment because of respiratory symptoms might have been overestimated because of the influenza A (H1N1) pandemic, which occurred during the study period. This also explains the high prevalence of diagnoses of influenza and URTI in patients treated at the emergency room of the tertiary care hospital. Likewise, upper respiratory tract symptoms, such as rhinorrhea and odynophagia, as well as fever, were more common in the adult patients presenting to the emergency room with a $\leq 6$-day history of respiratory symptoms, perhaps out of concern regarding the possibility of having $A(\mathrm{H} 1 \mathrm{~N} 1)$ influenza.

The adult patients who had a $\leq 6$-day history of respiratory symptoms were younger than were the other patients. It is known that elderly patients with pneumonia have lower body temperature and that it can take them longer to seek medical attention, increasing the likelihood of delayed diagnosis and delayed treatment. ${ }^{(11)} \mathrm{In}$ fact, the higher number of patients diagnosed with pneumonia in the 7-21 and $>21$ groups corroborates this finding.

A higher level of education was found in the group of adult patients who presented to the emergency room earlier ( $<7$ group). Studies have demonstrated that individuals with a higher level of education have a healthier behavior, have more information about their health, and clearly understand the instructions provided at discharge from the emergency room. ${ }^{(12)}$ In general, those with a higher level of education tend to make better health-related decisions. Therefore, considering the context of the influenza A ( $\mathrm{H} 1 \mathrm{~N} 1)$ epidemic, it is possible that these patients sought medical attention earlier for fear of this pathology.

In the adult patients, we found that a longer time from symptom onset to emergency room visit correlated with a greater need for hospitalization, longer hospital stays, and higher mortality. Respiratory symptoms are associated with various diseases and are considered significant predictors of mortality. ${ }^{(13)}$ Among respiratory symptoms, breathlessness is the most closely associated with mortality. ${ }^{(14)}$ In fact, in our study, we found that breathlessness was more common in the 7-21 and $>21$ groups than in the $<7$ group, probably indicating greater severity and chronicity of symptoms in the first two groups.

The present study has some methodological limitations. We included only patients presenting to the emergency room, and those probably represented cases that were more severe than those treated in primary care. In addition, the diagnoses were syndromic (i.e., the etiologic agent was not identified). However, despite these limitations, the study achieved its objective of showing the characteristics of patients with respiratory symptoms and is relevant for the evaluation of these patients in the context of emergency care. 
In conclusion, we have described the epidemiological profile of adult and pediatric patients presenting to an emergency room with respiratory symptoms. We found a high prevalence of respiratory symptoms as the motive for emergency room visits by adult and pediatric patients (in 28.7\% and 38.0\%, respectively). In addition, we found that a longer time from symptom onset to emergency room visit correlated with a greater need for hospitalization, longer hospital stays, and higher mortality among adults. Similar studies could inform decisions regarding the planning of prevention measures. Further longitudinal epidemiological studies are needed in order to clarify the risk factors for severe respiratory symptoms.

\section{References}

1. Pivetta ABDA, Botelho C. Prevalência de sintomas respiratórios e avaliação espirométrica em trabalhadores de marmorarias. J Pneumol. 1997;23(4):179-188.

2. Ruffino-Neto A, Carvalheiro JR. Doenças do aparelho respiratório e doenças infecciosas e parasitárias na morbidade referida pela população, Ribeirão Preto, SP, 1975. Medicina (Ribeirão Preto) 1982;15:79-83.

3. World Health Organization [homepage in the Internet]. Geneva: World Health Organization. [cited 2012 Oct 10]. The top 10 causes of death - Fact sheet $N^{\circ} 310$, Updated June 2011. Available from: http://www.who. $\mathrm{int} /$ mediacentre/factsheets/fs310/en/index.html

4. Portal da Saúde [homepage on the Internet]. Brasília: Ministério da Saúde. [cited 2012 Oct 10]. Sistema de informações hospitalares do SUS (SIH/SUS). Available from: http://portal.saude.gov.br/portal/saude/profissional/ visualizar_texto.cfm?idtxt $=29939$ \& $t$ janela $=1$

5. Greenberg SB. Respiratory viral infections in adults. Curr Opin Pulm Med. 2002;8(3):201-8.

6. Desalu 00, Ojo 00, Busari OA, Fadeyi A. Pattern of respiratory diseases seen among adults in an emergency room in a resource-poor nation health facility. Pan Afr Med J. 2011;9:24.

7. Valença LM, Restivo PC, Nunes MS. Seasonal variations in emergency room visits for asthma attacks in Gama, Brazil. J Bras Pneumol. 2006;32(4):284-9.

8. Tramuto F, Cusimano R, Cerame G, Vultaggio M, Calamusa G, Maida CM, et al. Urban air pollution and emergency room admissions for respiratory symptoms: a case-crossover study in Palermo, ltaly. Environ Health. 2011;10:31.

9. Backman AS, Blomqvist P, Lagerlund M, Carlsson-Holm E, Adami J. Characteristics of non-urgent patients. Crosssectional study of emergency department and primary care patients. Scand J Prim Health Care. 2008;26(3):181-7.

10. Zidouni N, Baough L, Laid Y, Chaulet P. Practical approach to lung health strategy in Algeria [Article in French]. Int J Tuberc Lung Dis. 2009;13(8):1029-37.

11. Matsuno O, Kataoka H, Takenaka R, Okubo F, Okamoto $\mathrm{K}$, Masutomo K, et al. Influence of age on symptoms and laboratory findings at presentation in patients with influenza-associated pneumonia. Arch Gerontol Geriatr. 2009;49(2):322-5.

12. Cutler DM, Lleras-Muney A. Understanding differences in health behaviors by education. J Health Econ. 2010;29(1):1-28.

13. Frostad A, Søyseth V, Andersen A, Gulsvik A. Respiratory symptoms as predictors of all-cause mortality in an urban community: a 30-year follow-up. J Intern Med. 2006;259(5):520-9.

14. Knuiman MW, James AL, Divitini ML, Ryan G, Bartholomew HC, Musk AW. Lung function, respiratory symptoms, and mortality: results from the Busselton Health Study. Ann Epidemiol. 1999;9(5):297-306. 


\section{About the authors}

\section{Denise Rossato Silva}

Adjunct Professor of Pulmonology. Universidade Federal do Rio Grande do Sul - UFRGS, Federal University of Rio Grande do Sul - School of Medicine, Porto Alegre, Brazil.

\section{Vinícius Pellegrini Viana}

Physician. Hospital de Clínicas de Porto Alegre, Porto Alegre, Brazil.

\section{Alice Mânica Müller}

Master's Student. Graduate Program in Pulmonology, Universidade Federal do Rio Grande do Sul - UFRGS, Federal University of Rio Grande do Sul - School of Medicine, Porto Alegre, Brazil.

\section{Ana Cláudia Coelho}

Physical Therapist. Hospital de Clínicas de Porto Alegre, Porto Alegre, Brazil.

\section{Gracieli Nadalon Deponti}

Master's Student. Graduate Program in Pulmonology, Universidade Federal do Rio Grande do Sul - UFRGS, Federal University of Rio Grande do Sul - School of Medicine, Porto Alegre, Brazil.

\section{Fernando Pohlmann Livi}

Professor. Universidade Federal do Rio Grande do Sul - UFRGS, Federal University of Rio Grande do Sul - School of Geography, Porto Alegre, Brazil.

\section{Paulo de Tarso Roth Dalcin}

Associate Professor of Pulmonology. Universidade Federal do Rio Grande do Sul - UFRGS, Federal University of Rio Grande do Sul - School of Medicine, Porto Alegre, Brazil. 